\title{
PKC Differentially Translocates during Spaced and Massed Training in Aplysia
}

\author{
Carole A. Farah, Daniel Weatherill, Tyler W. Dunn, and Wayne S. Sossin \\ Department of Neurology and Neurosurgery, Montreal Neurological Institute, McGill University, Montreal, Quebec H3A 2B4, Canada
}

Learning is highly regulated by the pattern of training. In Aplysia, an important organism for the development of cellular and molecular models of learning, spaced versus massed application of the same stimulus leads to different forms of memory. A critical molecular step underlying memory is the serotonin (5HT)-mediated activation of the novel PKC Apl II. Here, we demonstrate that activation of PKC Apl II is highly sensitive to the pattern of 5HT application. Spaced applications downregulate PKC translocation through PKA signaling, whereas massed applications lead to persistent translocation of PKC. Differential regulation of PKC translocation is mediated by competing feedback mechanisms that act through protein synthesis. These studies elucidate a fundamental molecular difference between spaced and massed training protocols.

\section{Introduction}

The formation of a memory is highly sensitive not only to the total amount of training, but also to the pattern of trials used during training. In particular, trials distributed over time (spaced training) are superior at generating long-term memories than trials presented at very short intervals (massed training) in every organism in which this has been studied (Sutton et al., 2002). Moreover, even when massed training gives an equivalent amount of memory, the underlying mechanisms activated by massed or spaced training trials may be distinct (Tully et al., 1994). Thus, the differences between spaced training and massed training may lie at the level of the molecular memory trace (Sossin, 2008).

An ideal model system to examine the mechanism for decoding the differences between patterns of training is the mollusk, Aplysia. Behavioral sensitization in Aplysia is caused in part by an increase in the strength of synaptic signaling between the mechanoreceptor sensory neurons and motor neurons, a process called synaptic facilitation (Kandel, 2001). Facilitation is mediated by release of serotonin (5HT) and can be observed in distinct time domains, which are called short-, intermediate-, and longterm facilitation (Byrne and Kandel, 1996). Four to five spaced applications of 5HT persistently activate PKA, and this is important for both the expression of intermediate-term facilitation (ITF) (Sutton and Carew, 2000; Sutton et al., 2001) and the induction of long-term facilitation (LTF) (Chain et al., 1999). In contrast, if the application of 5HT is continuous (25 min of con-

Received March 31, 2009; revised July 15, 2009; accepted July 16, 2009.

This work was supported by Canadian Institutes of Health Research (CIHR) Grant MOP 12046. C.A.F. is a postdoctoral fellow of the Fonds de la Recherche en Santé du Québec (FRSQ) and a Conrad Harrington fellow. D.W. has a scholarship from the FRSQ. T.W.D. is supported by a CIHR postdoctoral fellowship. W.S.S. is a James McGill Scholar and an FRSQ Chercheur National. We thank Peter McPherson and Philip Barker for helpful comments.

Correspondence should be addressed to Wayne S. Sossin, Department of Neurology and Neurosurgery, Montreal Neurological Institute, McGill University, BT 110, 3801 University Street, Montreal, QC H3A 2B4, Canada. E-mail: wayne.sossin@mcgill.ca.

D0I:10.1523/JNEUROSCI.1533-09.2009

Copyright $\odot 2009$ Society for Neuroscience $\quad$ 0270-6474/09/2910281-06\$15.00/0 tinuous 5HT), then these protocols are ineffective at inducing LTF and weaker at inducing ITF (Mauelshagen et al., 1998; Sutton et al., 2002). Although longer continuous applications of 5HT (90 min) do induce both ITF (Yanow et al., 1998) and LTF (Zhang et al., 1997), they do not persistently activate PKA (Müller and Carew, 1998; but see Kurosu et al., 2007), suggesting that this ITF may be mediated by a different molecular trace. Indeed, massed applications of $5 \mathrm{HT}$ persistently activate the novel PKC Apl II (Sossin, 1997).

In this study, we show that PKC Apl II translocation is differentially regulated by spaced versus massed applications of 5HT and that differential activation of PKC Apl II can explain some of the differences between spaced and massed training.

\section{Materials and Methods}

Aplysia cell culture preparation. Sensory neuron cultures were prepared following published procedures (Zhao et al., 2006; Farah et al., 2008).

Plasmid construction and microinjection of plasmid vectors. The pNEX3 enhanced green fluorescent protein (eGFP) PKC Apl II has been described previously, as has the injection procedure for expression in sensory neurons (Manseau et al., 2001; Zhao et al., 2006; Farah et al., 2008).

Confocal microscopy of Aplysia neurons. Live cell imaging was done as described previously (Farah et al., 2008). For spaced training, neurons received five applications of $10 \mu \mathrm{M} 5 \mathrm{HT}$ ( 5 min each) at an intertrial interval of $20 \mathrm{~min}$. For massed training, neurons received a single continuous application of $10 \mu \mathrm{M} 5 \mathrm{HT}$ for $90 \mathrm{~min}$. All experiments were performed at room temperature $\left(20-23^{\circ} \mathrm{C}\right)$.

Drug treatment. The phospholipase C inhibitor U-73122 (1-[6-[[17 $\beta$ methoxyestra-1,3,5(10)-trien-17-yl]amino]hexyl]-1 $H$-pyrrole-2,5-dione) and the translation inhibitors anisomycin and emetine were purchased from Sigma-Aldrich. The PKA inhibitors H-89 (5-isoquinolinesulfonamide), and KT5720 were purchased from Calbiochem.

Image analysis. The time series was analyzed using NIH Image J software as previously described (Zhao et al., 2006; Farah et al., 2008). The effect of $5 \mathrm{HT}$ was determined by comparing the degree of membrane association $\left(I_{\mathrm{m}} / I_{\mathrm{c}}\right)$ ratio before and after $5 \mathrm{HT}$ (Post/Pre); the fold change is the translocation ratio. For measuring desensitization, the translocation ratio after the first $5 \mathrm{HT}$ application (post $5 \mathrm{HT} \# 1$ ) for spaced train- 

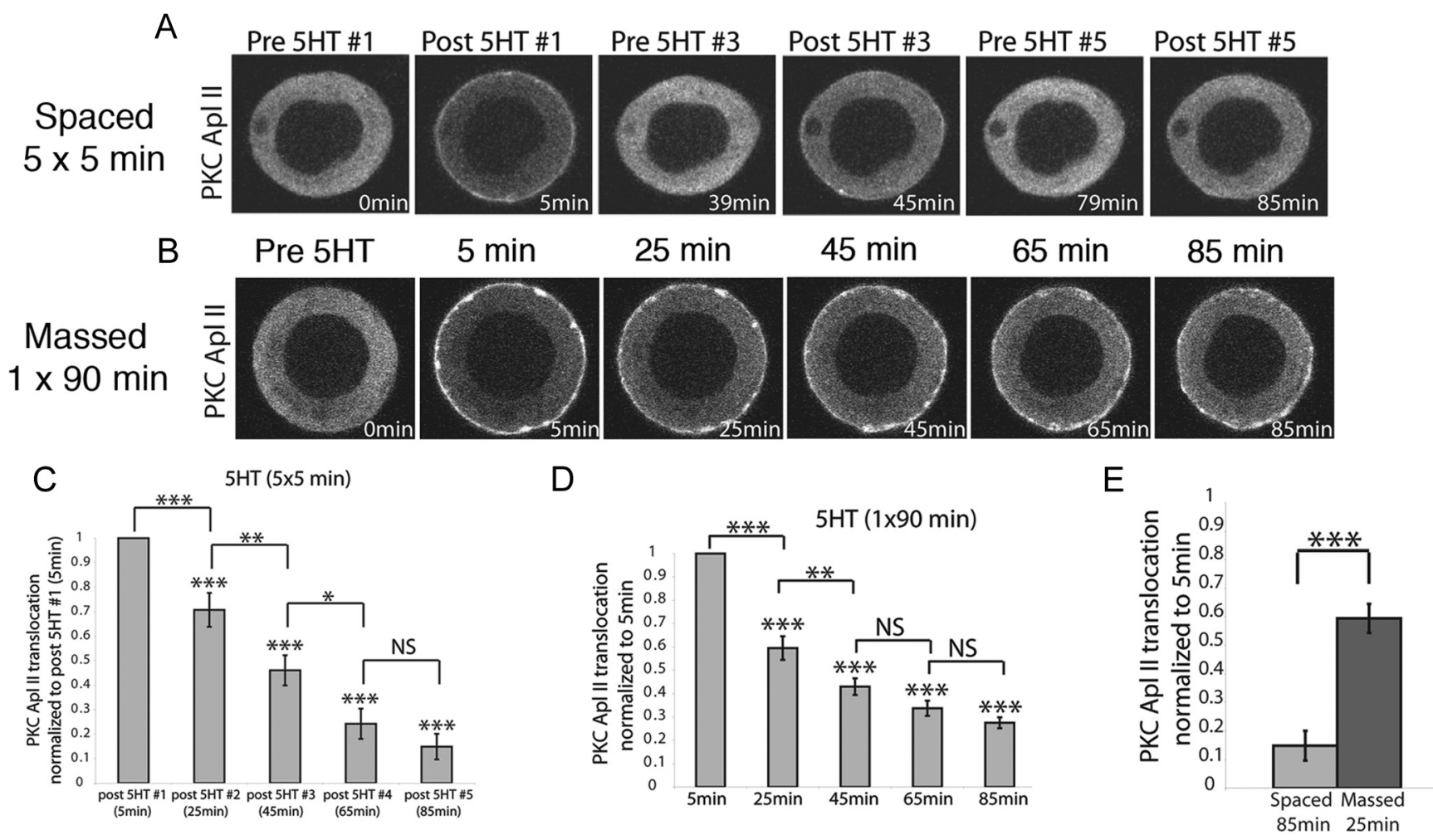

Figure 1. PKC Apl II translocation strongly desensitizes in response to spaced applications of 5HT to sensory neurons. $\boldsymbol{A}, \boldsymbol{B}$, Representative confocal fluorescence images of sensory neurons expressing eGFP-PKC Apl II during spaced $(\boldsymbol{A})$ or massed $(\boldsymbol{B})$ applications of 5 HT. $\boldsymbol{C}, \boldsymbol{D}$, Repeated-measures ANOVA performed on the translocation ratios shows significant difference between the means for both spaced training $\left[F_{(51,4)}=8.1, p<0.001\right](C)$ and massed training $\left[F_{(104,4)}=43.5, p<0.001\right](\boldsymbol{D})$. Post hoc Newman-Keuls test was used to compare the decrease in translocation compared with post 5 HT \#1 (shown over bars) and to determine cumulative desensitization with subsequent $5 \mathrm{HT}$ pulses or at subsequent times $\left({ }^{*} p<0.05\right.$, ${ }^{* *} p<0.01,{ }^{* * *} p<0.001$; NS, not significant), $n=13(\boldsymbol{C})$ and $n=21$ (D). Error bars are SEM. $\boldsymbol{E}$, Comparison between translocation after the fifth $5 \mathrm{HT}$ pulse and after 25 min of continuous $5 \mathrm{HT}$ using a two-tailed unpaired Student's $t$ test on normalized desensitization $\left({ }^{* * *} p<0.001\right)$.

ing or post 5 min application of $5 \mathrm{HT}$ for massed training was used to normalize all subsequent translocation ratios for the same cell.

\section{Results}

PKC translocation desensitizes differentially to spaced or continuous applications of $5 \mathrm{HT}$

To monitor PKC activation, we followed the translocation of eGFP-tagged PKC Apl II from the cytoplasm to the plasma membrane in cultured Aplysia sensory neurons (Zhao et al., 2006; Farah et al., 2008). The activity of eGFP-PKC Apl II is indistinguishable from the activity of nontagged PKC Apl II and the level of overexpression under these conditions is modest (Manseau et al., 2001). Since PKCs are activated by the binding of the membrane-associated lipids, diacylglycerol and phosphatidylserine, translocation is highly correlated with activation (Zhao et al., 2006; Farah et al., 2008).

To characterize PKC Apl II activation during "training," Aplysia sensory neurons, previously microinjected with plasmid DNA encoding eGFP-PKC Apl II, received either "spaced training": five applications of $10 \mu \mathrm{M} 5 \mathrm{HT}$ ( 5 min each) spaced $20 \mathrm{~min}$ apart, a standard protocol for inducing ITF and LTF, or "massed training": a continuous 90 min application of 5-HT. During the first 5 min 5HT treatment, eGFP-PKC Apl II translocated from the cytosol to the plasma membrane (Fig. $1 A$ ). When 5 HT was washed off, the protein reverted back to the cytosol. When 5HT was added again 15 min later, eGFP-PKC Apl II translocation decreased significantly compared with the first application of 5HT, and by the fifth $5 \mathrm{HT}$ treatment, very little translocation was observed (Fig. $1 A$; quantified in Fig. $1 C$ ). The decrease in the ability of $5 \mathrm{HT}$ to induce translocation after previous applications of $5 \mathrm{HT}$ is a form of desensitization, and this term will be used throughout this study. eGFP-PKC Apl II translocation also decreased over time when the application of 5HT was continuous (Fig. $1 \mathrm{~B}$; quantified in Fig. $1 D$ ). To compare desensitization during those two paradigms, we normalized for the total amount of time when the neurons were exposed to 5HT, comparing the 85 min time point $(5 \times 5 \mathrm{~min} 5 \mathrm{HT})$ for spaced with the $25 \mathrm{~min}$ time point in massed training. Desensitization is much greater for spaced-85 min than for massed-25 min application of 5HT (Fig. $1 E)$. Moreover, since PKC is retained on the membrane during massed training, but not during spaced training, there will be considerably more PKC activation during massed training than during spaced.

\section{PKA mediates desensitization}

PKC activation was not required for the initial desensitization (supplemental Fig. S1, available at www.jneurosci.org as supplemental material). In addition to PKC, 5HT activates PKA in sensory neurons (Castellucci et al., 1982; Müller and Carew, 1998). To test whether PKA activity was required for 5HT-dependent desensitization of PKC Apl II translocation, spaced applications of 5HT were performed in the presence of KT5720, a potent specific cell-permeable inhibitor of PKA (Angers et al., 2002). There was no effect of KT5720 on the initial translocation of PKC Apl II post 5HT \#1 (supplemental statistics, available at www. jneurosci.org as supplemental material). However, KT5720 de- 

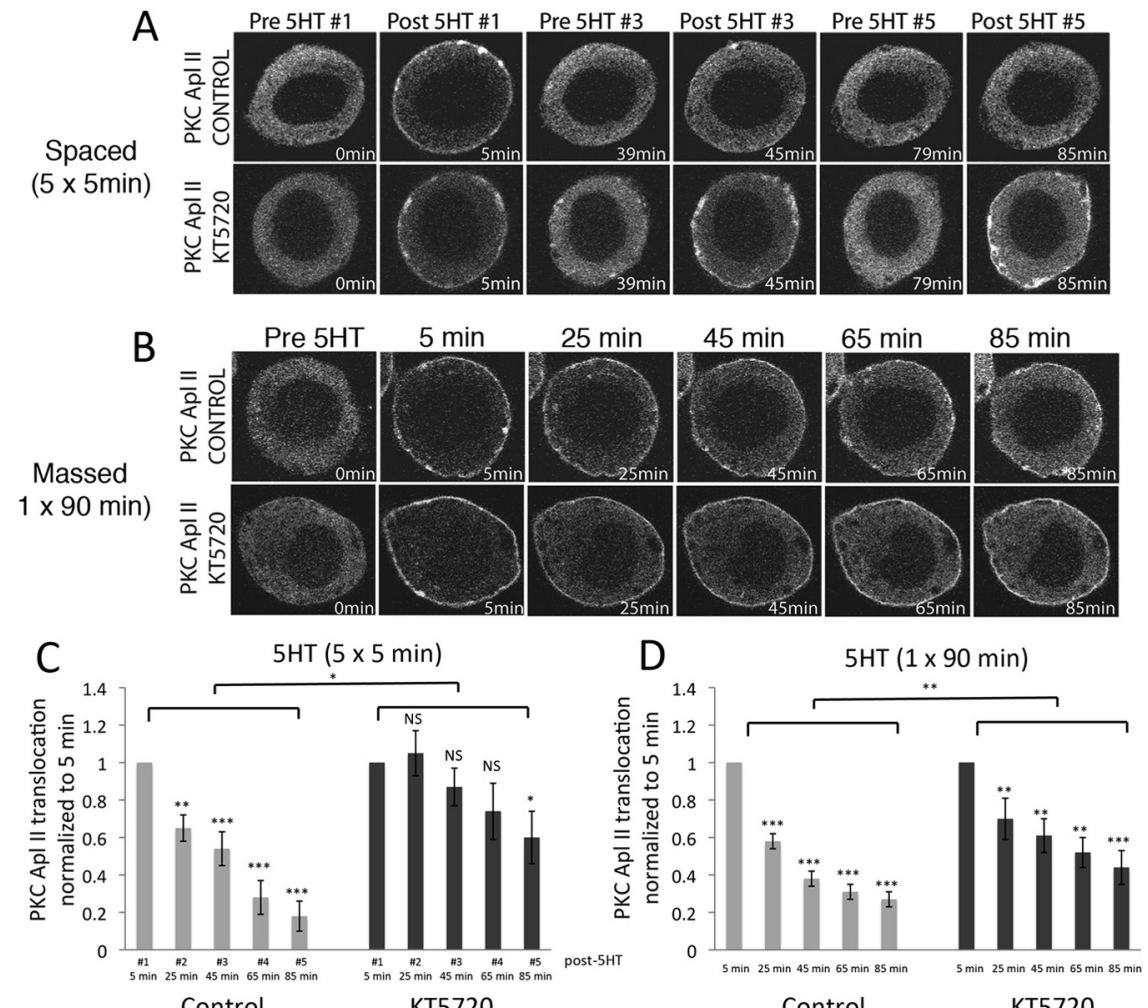

Contro

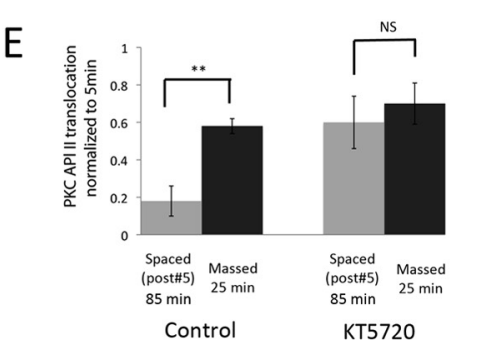

Figure 2. Inhibition of PKA decreases 5HT-dependent desensitization of PKC Apl II translocation in sensory neurons. $\boldsymbol{A}, \boldsymbol{B}$, Representative confocal fluorescence images of sensory neurons expressing eGFP-PKC Apl II during spaced $(\boldsymbol{A})$ or massed $(\boldsymbol{B})$ applications of 5HT in the absence or presence of the PKA inhibitor KT5720 (10 $\mu \mathrm{M})$. C, D, Two-way ANOVA performed on the translocation ratios shows a significant effect of both $\mathrm{KT} 5720\left[F_{(60,1)}=9.33, p<0.0001\right]$ and time $\left[F_{(60.4)}=7.84, p<0.001\right]$, with no interaction between time and drug for spaced training $(C)$ and a significant effect of $K T 5720\left[F_{(80,1)}=10.4, p<0.01\right]$ and time $\left[F_{(80,4)}=12.0 p<0.001\right]$ with no interaction between time and drug for massed training (D). Repeated-measures ANOVA performed on the translocation ratios shows significant difference between the means for control neurons $\left[F_{(36,4)}=23.6, p<\right.$ $0.001]$ and for neurons treated with $\mathrm{KT} 5720\left[F_{(34,4)}=3.02, p<0.05\right]$ for spaced training $(C)$ and significant differences between the means for control neurons $\left[F_{(44,4)}=40.9, p<0.001\right]$ and for neurons treated with $\mathrm{KT} 5720\left[F_{(44,4)}=7.4, p<0.01\right]$ for massed training (D). Posthoc Newman-Keuls test was used to compare decreases in translocation compared with post $5 \mathrm{HT} \# 1\left({ }^{*} p<0.05\right.$, ${ }^{* *} p<0.01,{ }^{* * *} p<0.001$; NS, not significant), $n=8-12(\boldsymbol{C})$ and $n=9(\boldsymbol{D})$. Error bars are SEM. $\boldsymbol{E}$, Comparison between translocation after the fifth $5 \mathrm{HT}$ pulse and after 25 min of continuous $5 \mathrm{HT}$ in the presence or absence of KT5720 using a two-tailed unpaired Student's $t$ test on normalized data $\left({ }^{* *} p<0.01\right.$; NS, not significant).

creased desensitization of eGFP-PKC Apl II translocation for both spaced (Fig. 2A; quantified in Fig. 2C). and massed 5HT applications (Fig. $2 B$; quantified in Fig. $2 D$ ). In the presence of the PKA inhibitor, there was no longer a difference between 25 min of 5HT given in a spaced or massed manner (Fig. $2 E$ ). Desensitization was also decreased after spaced training with an independent inhibitor of the PKA pathway, H-89 (Hidaka et al., 1990) (supplemental Fig. S2, available at www.jneurosci.org as supplemental material).

PKC translocation reverses within $90 \mathrm{~s}$ after $5 \mathrm{HT}$ is washed off (supplemental statistics, available at www.jneurosci.org as supplemental material). In contrast, activation of PKA in sensory neurons may be prolonged because of the long half-time of cAMP after removal of 5HT (10-15 min) (Bernier et al., 1982; Castellucci et al., 1982; Bacskai et al., 1993). Thus, during spaced training, PKA may be able to act during the interstimulus interval. Indeed, treatment with KT5720 only during the wash between the 5HT \#1 and 5HT \#2 applications blocked desensitization of PKC Apl II translocation (supplemental Fig. S3, available at www.jneurosci.org as supplemental material). Consistent with the action of KT5720 to inhibit desensitization occurring during the interval between 5HT treatments, we found that desensitization was delayed. No desensitization was observed 5 min after the first pulse, desensitization was maximal 15-30 min after 5HT washout, and the ability of 5HT to translocate eGFP-PKC Apl II to the membrane recovered after 45 min (supplemental Fig. S4, available at www.jneurosci.org as supplemental material).

\section{Protein synthesis differentiates spaced and massed training}

Some forms of ITF require protein synthesis (Sutton et al., 2001). Moreover, spaced versus massed application of 5HT may affect protein synthesis through different mechanisms (Carroll et al., 2006). We thus examined whether inhibiting translation would affect desensitization. Anisomycin inhibited desensitization during spaced applications of 5HT (Fig. 3A; quantified in Fig. $3 C$ ). This suggests that protein translation downstream of spaced applications produces a protein that enhances desensitization.

Strikingly, anisomycin had the opposite effect on desensitization of PKC Apl II translocation during continuous application of $5 \mathrm{HT}$, where protein synthesis inhibition strongly increased desensitization (Fig. 3B; quantified in Fig. 3D). This finding suggests that protein synthesis downstream of continuous $5 \mathrm{HT}$ applications produces a protein that inhibits desensitization.

Anisomycin had no effect on its own (supplemental statistics, available at www.jneurosci.org as supplemental material). Emetine, another protein synthesis inhibitor, had the same effect as anisomycin during continuous application of 5HT (supplemental Fig. S5, available at www.jneurosci.org as supplemental material). Thus, in the absence of protein synthesis, massed training caused much greater desensitization than spaced training, the opposite of what occurs in the presence of protein synthesis (Fig. 3E). Even in the absence of protein synthesis, desensitization depended on PKA as KT5720 still decreased desensitization during continuous $5 \mathrm{HT}$ application in the presence of protein synthesis 
inhibitors (supplemental Fig. S6, available at www.jneurosci.org as supplemental material).

\section{Discussion}

We have revealed several novel facts concerning desensitization of the PKC response in sensory neurons of Aplysia. First, a large component of desensitization is mediated by PKA. Second, desensitization is distinct, depending on the spacing of 5HT applications. Finally, there is an important feedback mechanism whereby 5 HT-dependent activation of protein synthesis regulates the level of desensitization.

5HT acts via G-protein-coupled receptors (GPCRs). Most responses to GPCRs desensitize through phosphorylation and/or endocytosis of the GPCR itself (Wolfe and Trejo, 2007). However, desensitization could also occur downstream of the receptor. Translocation of PKC Apl II by 5 HT depends on the joint activation of phospholipase $\mathrm{C}$ and phospholipase D (Farah et al., 2008), and desensitization could also be the result of downregulation of these signal transduction pathways.

\section{Translocation of PKC may mediate differences between spaced and massed application of 5 $\mathrm{HT}$}

To address complex behavioral traits at the level of individual neurons, we must extract the fundamental constraints of signal transduction that have implications for learning events. There has been considerable attention to the difference between spaced and massed applications of $5 \mathrm{HT}$ as a model for spaced versus massed differences seen in memory formation (Müller and Carew, 1998; Sutton and Carew, 2000; Sutton et al., 2002). A number of the specific characteristics of PKC and PKA activation make a battle between these kinases an attractive mechanism to differentiate spaced versus massed training. First, after 5HT is removed, PKC appears to be inactivated faster than PKA; thus, there is less activation by PKC during spaced training than by PKA, whose activity persists after the stimulus is gone. Second, due to the desensitization of the PKC response by PKA, the ability to activate PKC by subsequent stimuli is decreased by spaced applications. In contrast, massed applications allow for persistent translocation of PKC, and PKC activation can downregulate 5HT-mediated activation of PKA in sensory neurons (Sugita et al., 1997). Finally, these initial differences are greatly enhanced by two feedback mechanisms through protein translation (Fig. 4).
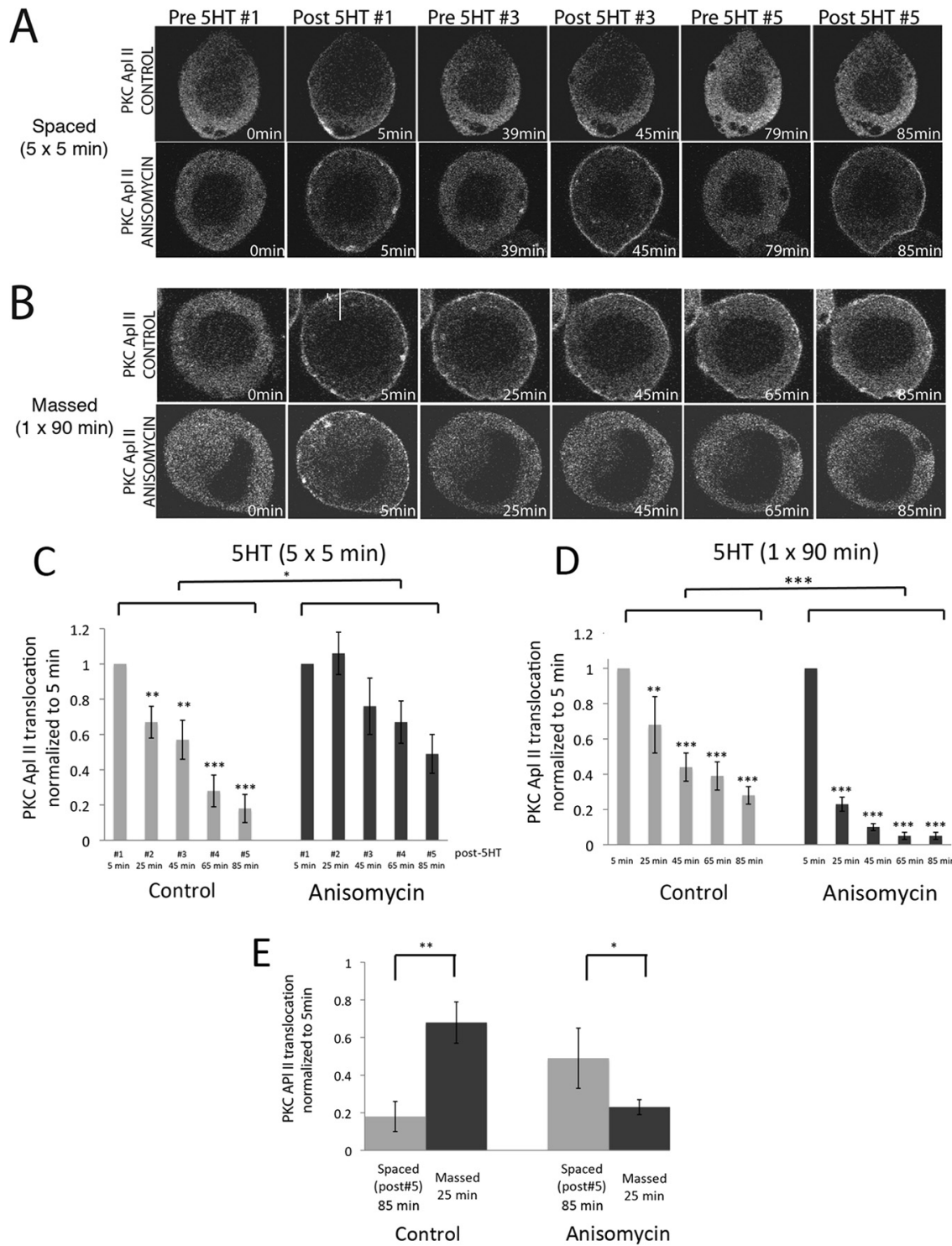

Figure 3. Anisomycin inhibits desensitization during spaced applications but strongly increases it during massed application of $5 \mathrm{HT}$ to sensory neurons. $A, B$, Representative confocal fluorescence images of Aplysia sensory neurons expressing eGFP-PKC Apl II during spaced applications of $5 \mathrm{HT}(\boldsymbol{A})$ or massed applications of $5 \mathrm{HT}$ in the absence or presence of the translation inhibitor anisomycin $(50 \mu \mathrm{M})(\boldsymbol{B}) . \mathbf{C}, \mathbf{D}$, Two-way ANOVA performed on the translocation ratios shows a significant effect of both anisomycin $\left[F_{(65,1)}=4.09, p<0.05\right]$ and time $\left[F_{(65,4)}=3.47, p<0.05\right]$ with no interaction between time and anisomycin for spaced training $(C)$ and a significant effect of both anisomycin $\left[F_{(100,1)}=43.9, p<\right.$ $0.001]$ and time $\left[F_{(100,4)}=40.6, p<0.001\right]$ with no interaction between anisomycin and time for massed training $(\boldsymbol{D})$. Repeated-measures ANOVA performed on the translocation ratios shows significant difference between the means for control neurons, $\left[F_{(39,4)}=31.6, p<0.001\right]$ but not for the neurons treated with anisomycin $\left[F_{(34,2)}=2.5, p=0.07\right]$ after spaced training $(C)$ and significant difference between the means for the control neurons $\left[F_{(29,4)}=6.7, p<0.01\right]$ and the anisomycin-treated neurons $\left[F_{(79,4)}=93.5, p<0.001\right]$ for massed training (D). Post hoc Newman-Keuls test was used to compare decreases in translocation compared with post $5 \mathrm{HT} \# 1{ }^{*} p<0.05,{ }^{* *} p<0.01$, ${ }^{* * *} p<0.001$; NS, not significant). $\boldsymbol{E}$, Comparison between translocation after the fifth $5 \mathrm{HT}$ pulse and after $25 \mathrm{~min}$ of continuous $5 \mathrm{HT}$ in the presence or absence of anisomycin using a two-tailed unpaired Student's $t$ test on normalized data $\left({ }^{* *} p<0.01,{ }^{*} p<0.05\right)$.

\section{Role of protein synthesis in distinguishing spaced versus massed application of $5 \mathrm{HT}$}

Inhibition of protein synthesis differentially affected desensitization to massed and spaced application of 5HT in sensory neurons, increasing desensitization after massed applications and decreasing it after spaced applications. These differential effects could be explained by differential regulation of protein synthesis. Spaced applications of 5HT are more likely to activate cap-dependent translation through the TOR pathway (Carroll et al., 2006), 

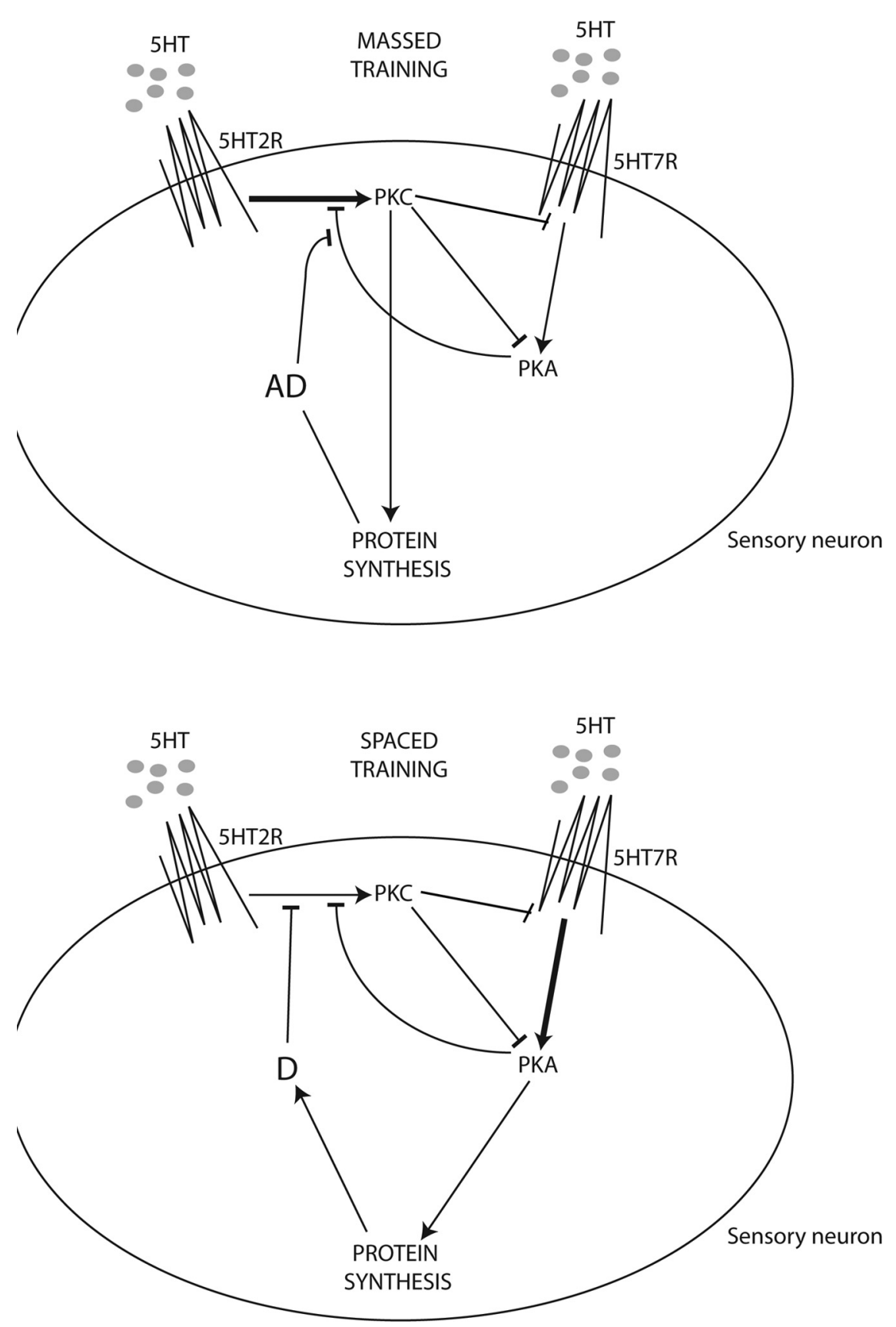

Figure 4. Model for desensitization of PKC Apl II translocation. In the sensory neuron, 5HT activates a 5HT receptor coupled to PLC activation (5HT2R) that leads to PKC Apl II translocation. At the same time, 5HT would be activating a 5HT receptor coupled to adenylate cyclase leading to activation of PKA (5HT7R). During massed training, PKC would inhibit PKA activity at both the level of CAMP production and at some point downstream of PKA as previously demonstrated (Sugita et al., 1997). At the same time, PKC would trigger synthesis of an anti-desensitization protein (AD) that protects PKC Apl II translocation from desensitizing. The stronger activation of PKC is depicted with a thick arrow. During spaced training, PKA would inhibit translocation of PKC ApI II. PKA would also trigger synthesis of a desensitization protein (D) that increases desensitization of PKC Apl II translocation. Arrowheads are activating and bars are inhibiting. The stronger activation of PKA is depicted by a thick arrow. This schematic is not intended to show PKC Apl II translocation but, rather, the molecular pathways involved in its desensitization process.

whereas continuous application of 5-HT may decrease capdependent translation through dephosphorylation of eIF4E (Dyer and Sossin, 2000). Interestingly, the decrease in eIF4E phosphorylation is downstream of PKC activation (Dyer and Sossin, 2000). This suggests a positive feedback loop in which $\mathrm{PKC}$ activated by $5 \mathrm{HT}$ will inhibit the desensitization of the PKC response. Since, after washout of 5HT, PKC translocates quickly back to the cytoplasm (Zhao et al., 2006), spaced applications are less likely to activate the PKC-dependent translational response than when $\mathrm{PKC}$ remains on the membrane during continuous applications of 5HT. Instead, we propose that spaced applications of 5 HT lead to persistent PKA activation and the production of a protein that increases PKC desensitization. Activation of PKA has been implicated in a protein synthesis-dependent increase in overall endocytosis (Hu et al., 1993) and, thus, increased endocytosis of the GPCR coupled to PKC activation is a possible mechanism for the protein synthesisdependent desensitization.

\section{Physiological significance of desensitization of the $\mathrm{PKC}$ response} PKC activation is important for many aspects of the synaptic plasticity underlying memory formation in Aplysia (Sossin, 2007). Thus, desensitization of the PKC response will have important physiological consequences. Indeed, the ability of $5 \mathrm{HT}$ to mediate facilitation at depressed synapses, a response mediated by PKC Apl II (Manseau et al., 2001), does show desensitization (Dumitriu et al., 2006). Massed training may be poorer at inducing longterm memory because of inhibition of the formation of long-term memory (Isabel et al., 2004). PKC could represent this inhibitor. Continued PKC activation decreases cap-dependent translation (Yanow et al., 1998), and this type of translation, defined by its sensitivity to rapamycin, is required for LTF (Hu et al., 2006). Moreover, this may also explain the lack of persistent activation of PKA by massed training, since this also requires translation, probably cap-dependent translation (Müller and Carew, 1998). Indeed, inhibition of PKC does not block this form of ITF (Sutton and Carew, 2000). Although the same amount of $5 \mathrm{HT}$ or training given in a massed manner (25 min of 5HT) does not lead to LTF, when massed applications of 5HT are prolonged (90 $\mathrm{min}$ ), LTF is induced (Zhang et al., 1997). It is possible that PKC may participate in this form of LTF, perhaps through degradation of the cAMP response element-binding protein repressor (Upadhya et al., 2004).

It should be noted that all the experiments in this study used isolated sensory neurons. Although the motor neuron also plays an important role in facilitation (Glanzman, 2008), neither PKC Apl I nor PKC Apl II was translocated by $5 \mathrm{~min}$ of $5 \mathrm{HT}$ in the motor neuron (Zhao et al., 2006). Thus, we did not examine desensitization in the motor neuron. Cleavage of PKC Apl III is important for the maintenance of changes in the motor neuron associated with facilitation (Villareal et al., 2009), and it will be interesting to see whether this mechanism of activation is also sensitive to the pattern of stimulation. Recently, an important 
feedback from the motor neuron has been discovered that regulates protein synthesis in the sensory neuron (Cai et al., 2008; Wang et al., 2009) and may also regulate PKC activation (Hawkins et al., 2006). In the future, it will be important to examine the impact of this feedback and whether desensitization of PKC Apl II differs in isolated sensory neurons and sensory neurons connected to the motor neuron.

\section{Physiological significance of massed versus spaced training in Aplysia}

Sensitization is a nonassociative memory attributable to a noxious experience. It is not clear in naturally behaving animals whether or not these noxious experiences will occur in a massed or spaced manner. The serotonergic neurons in Aplysia fire repetitively and release 5HT after stimulation of the tail nerve, an analog of tail shock, and this release is prolonged (up to $5 \mathrm{~min}$ ) (Marinesco et al., 2004). Furthermore, there is a positive feedback system such that serotonin release increases excitability of these cells, suggesting the possibility that release of 5HT may be prolonged even more after a particularly strong shock (Marinesco et al., 2004). Thus, massed application of 5HT could be an analog for a severe or prolonged noxious event that is experienced only once.

\section{References}

Angers A, Fioravante D, Chin J, Cleary LJ, Bean AJ, Byrne JH (2002) Serotonin stimulates phosphorylation of Aplysia synapsin and alters its subcellular distribution in sensory neurons. J Neurosci 22:5412-5422.

Bacskai BJ, Hochner B, Mahaut-Smith M, Adams SR, Kaang BK, Kandel ER, Tsien RY (1993) Spatially resolved dynamics of cAMP and protein kinase A subunits in Aplysia sensory neurons. Science 260:222-226.

Bernier L, Castellucci VF, Kandel ER, Schwartz JH (1982) Facilitatory transmitter causes a selective and prolonged increase in adenosine $3^{\prime}: 5^{\prime}$-monophosphate in sensory neurons mediating the gill and siphon withdrawal reflex in Aplysia. J Neurosci 2:1682-1691.

Byrne JH, Kandel ER (1996) Presynaptic facilitation revisited: state and time dependence. J Neurosci 16:425-435.

Cai D, Chen S, Glanzman DL (2008) Postsynaptic regulation of long-term facilitation in Aplysia. Curr Biol 18:920-925.

Carroll M, Dyer J, Sossin WS (2006) Serotonin increases phosphorylation of synaptic 4EBP through TOR, but eukaryotic initiation factor 4E levels do not limit somatic cap-dependent translation in Aplysia neurons. Mol Cell Biol 26:8586-8598.

Castellucci VF, Nairn A, Greengard P, Schwartz JH, Kandel ER (1982) Inhibitor of adenosine $3^{\prime}: 5^{\prime}$-monophosphate-dependent protein kinase blocks presynaptic facilitation in Aplysia. J Neurosci 2:1673-1681.

Chain DG, Casadio A, Schacher S, Hegde AN, Valbrun M, Yamamoto N, Goldberg AL, Bartsch D, Kandel ER, Schwartz JH (1999) Mechanisms for generating the autonomous cAMP-dependent protein kinase required for long-term facilitation in Aplysia. Neuron 22:147-156.

Dumitriu B, Cohen JE, Wan Q, Negroiu AM, Abrams TW (2006) Serotonin receptor antagonists discriminate between PKA- and PKC-mediated plasticity in Aplysia sensory neurons. J Neurophysiol 95:2713-2720.

Dyer JR, Sossin WS (2000) Regulation of eukaryotic initiation factor 4E phosphorylated in the nervous system of Aplysia californica. J Neurochem 75:872-881.

Farah CA, Nagakura I, Weatherill D, Fan X, Sossin WS (2008) Physiological role for phosphatidic acid in the translocation of the novel protein kinase C Apl II in Aplysia neurons. Mol Cell Biol 28:4719-4733.

Glanzman DL (2008) New tricks for an old slug: the critical role of postsynaptic mechanisms in learning and memory in Aplysia. Prog Brain Res 169:277-292.

Hawkins RD, Kandel ER, Bailey CH (2006) Molecular mechanisms of memory storage in Aplysia. Biol Bull 210:174-191.

Hidaka H, Hagiwara M, Chijiwa T (1990) Molecular pharmacology of protein kinases. Neurochem Res 15:431-434.
Hu JY, Wu F, Schacher S (2006) Two signaling pathways regulate the expression and secretion of a neuropeptide required for long-term facilitation in Aplysia. J Neurosci 26:1026-1035.

Hu Y, Barzilai A, Chen M, Bailey CH, Kandel ER (1993) 5-HT and cAMP induce the formation of coated pits and vesicles and increase the expression of clathrin light chain in sensory neurons of Aplysia. Neuron 10:921-929.

Isabel G, Pascual A, Preat T (2004) Exclusive consolidated memory phases in Drosophila. Science 304:1024-1027.

Kandel ER (2001) The molecular biology of memory storage: a dialogue between genes and synapses. Science 294:1030-1038.

Kurosu T, Hernández AI, Schwartz JH (2007) Serotonin induces selective cleavage of the pka ri subunit but not rii subunit in Aplysia neurons. Biochem Biophys Res Commun 359:563-567.

Manseau F, Fan X, Hueftlein T, Sossin W, Castellucci VF (2001) Ca2+independent PKC Apl II mediates the serotonin induced facilitation at depressed synapses in Aplysia. J Neurosci 21:1247-1256.

Marinesco S, Kolkman KE, Carew TJ (2004) Serotonergic modulation in Aplysia. I. Distributed serotonergic network persistently activated by sensitizing stimuli. J Neurophysiol 92:2468-2486.

Mauelshagen J, Sherff CM, Carew TJ (1998) Differential induction of longterm synaptic facilitation by spaced and massed applications of serotonin at sensory neuron synapses of Aplysia californica. Learn Mem 5:246-256.

Müller U, Carew TJ (1998) Serotonin induces temporally and mechanistically distinct phases of persistent PKA activity in Aplysia sensory neurons. Neuron 21:1423-1434.

Sossin WS (1997) An autonomous kinase is formed from the $\mathrm{Ca}^{2+}$. independent protein kinase C Apl II during long-term facilitation in Aplysia. Learn Mem 3:389-401.

Sossin WS (2007) Isoform specificity of protein kinase Cs in synaptic plasticity. Learn Mem 14:236-246.

Sossin WS (2008) Molecular memory traces. Prog Brain Res 169:3-25.

Sugita S, Baxter DA, Byrne JH (1997) Modulation of a cAMP/protein kinase A cascade by protein kinase $\mathrm{C}$ in sensory neurons of Aplysia. J Neurosci 17:7237-7244.

Sutton MA, Carew TJ (2000) Parallel molecular pathways mediate expression of distinct forms of intermediate-term facilitation at tail sensorymotor synapses in Aplysia. Neuron 26:219-231.

Sutton MA, Masters SE, Bagnall MW, Carew TJ (2001) Molecular mechanisms underlying a unique intermediate phase of memory in Aplysia. Neuron 31:143-154.

Sutton MA, Ide J, Masters SE, Carew TJ (2002) Interaction between amount and pattern of training in the induction of intermediate- and long-term memory for sensitization in Aplysia. Learn Mem 9:29-40.

Tully T, Preat T, Boynton SC, Del Vecchio M (1994) Genetic dissection of consolidated memory in Drosophila. Cell 79:35-47.

Upadhya SC, Smith TK, Hegde AN (2004) Ubiquitin-proteasomemediated CREB repressor degradation during induction of long-term facilitation. J Neurochem 91:210-219.

Villareal G, Li Q, Cai D, Fink AE, Lim T, Bougie JK, Sossin WS, Glanzman DL (2009) Role of protein kinase $C$ in the induction and maintenance of serotonin-dependent enhancement of the glutamate response in isolated siphon motor neurons of Aplysia californica. J Neurosci 29:5100-5107.

Wang DO, Kim SM, Zhao Y, Hwang H, Miura SK, Sossin WS, Martin KC (2009) Synapse- and stimulus-specific local translation during longterm neuronal plasticity. Science 324:1536-1540.

Wolfe BL, Trejo J (2007) Clathrin-dependent mechanisms of G proteincoupled receptor endocytosis. Traffic 8:462-470.

Yanow SK, Manseau F, Hislop J, Castellucci VF, Sossin WS (1998) The biochemical pathways by which serotonin regulates translation in the nervous system of Aplysia. J Neurochem 70:572-583.

Zhang F, Endo S, Cleary LJ, Eskin A, Byrne JH (1997) Role of transforming growth factor-beta in long-term synaptic facilitation in Aplysia. Science 275:1318-1320.

Zhao Y, Leal K, Abi-Farah C, Martin KC, Sossin WS, Klein M (2006) Isoform specificity of PKC translocation in living Aplysia sensory neurons and a role for Ca2+-dependent PKC APL I in the induction of intermediate-term facilitation. J Neurosci 26:8847-8856. 